\title{
Proceeding
}

Supplementary Issue: Spring Conferences of Sports Science. 15th Convention and Workshop of the International Network of Sport and Health Science, 5-8 June 2019. University of Las Palmas de Gran Canaria, Las Palmas de Gran Canaria, Spain.

\section{Case study on the choices to be made to limit the damage of the transitional period}

\author{
DANTE FORTE 14 , ANDREA CECILIANI ${ }^{2}$, ARIO FEDERICl ${ }^{3}$, GAETANO ALTAVILLA $^{4}$ \\ 1 University of Salerno, Italy \\ 2 University of Bologna, Italy \\ 3 University Carlo Bo of Urbino, Italy \\ ${ }^{4}$ University of Split, Croatia
}

\begin{abstract}
Following the transition period, there is a clear reduction in performance levels for individual skills such as jumping, speed, dexterity and strength of the upper limbs. A compensatory working hypothesis is urgently needed to mitigate the damage. The aim of the study is to investigate the motivation, thought and self-criticism of athletes on this subject through the case study with the method of administration of a questionnaire that evaluate the propensity to train in the transition period and preference for methodological choices. The administration was done through a special online platform, in total anonymity so as not to incur in false data. The study is submitted to volleyball athletes of different sex and age. The study involved 67 athletes divided into 3 groups: 19 boys aged between 18 and 29 years, 22 girls aged between 13 and 18 years and 26 other girls aged between 19 and 30 years. From the study conducted shows a favourable propensity to continue the activity during this period by athletes preferring group activities over solo activities. And there is a tendency to leave the decision on the planning of activities to the figure of the coach. In conclusion, the study gives an immediate response to the hypothesis of solving the problem by finding fertile ground in the will of the athletes and in any case ascertains the functionality of the method to be adopted for a study with a large and representative sports sample. Keywords: Performance; Sport Skills; Questionnaire.
\end{abstract}

\section{Cite this article as:}

Forte, D., Ceciliani, A., Federici, A., \& Altavilla, G. (2019). Case study on the choices to be made to limit the damage of the transitional period. Journal of Human Sport and Exercise, 14(4proc), S584-S591. doi:https://doi.org/10.14198/jhse.2019.14.Proc4.16

Corresponding author. University of Salerno, Italy.

E-mail: danteforte@outlook.it

Supplementary Issue: Spring Conferences of Sports Science. 15th Convention and Workshop of the International Network of Sport and Health Science, 5-8 June 2019. University of Las Palmas de Gran Canaria, Las Palmas de Gran Canaria, Spain. JOURNAL OF HUMAN SPORT \& EXERCISE ISSN 1988-5202

(c) Faculty of Education. University of Alicante

doi:10.14198/jhse.2019.14.Proc4.16

S584 | 2019| Proc4 | VOLUME 14

C 2019 University of Alicante 


\section{INTRODUCTION}

The transition period (D'elia et al., 2019), from the end of competitive activity to the beginning of the following sports season, leads to a reduction in performance (Tiziana et al., 2017), as we have seen from previous research (Forte et. al, 2019, Forte, Altavilla, 2018,), so there is an urgent need for compensatory work to mitigate the damage. The transition period is particularly important for the serve (Parisi, Raiola, 2014) and technological use of training (Ferrara et al., 2019) in testing before the regular season. Performance has to be evaluated continuously (D'lsanto et al., 2019) to plan the training session especially in volleyball. The transition phase is generally self-managed by the athlete. This system most of the time does not work or is unsuitable: when the activity resumes, there are many problems to be solved (Di Tore et al., 2018, D'elia et al., 2018, Raiola 2017, Raiola, Di Tore, 2017, Di Tore, Gaetano, 2012).

In reality, the transitional period without usual training rhythms can be managed in 3 ways:

A. Insufficient maintenance activities such as quality and quantity. This is what usually happens: the programs carried out by the athlete are unsuitable or poorly managed. You are content to enter the weight room when you want and hardly in August, do not like alternative activities such as beach volleyball, tennis and basketball. Inevitably, you lose your physical qualities and you gain weight.

B. Alternative competitive activities. Some players, as soon as the indoor activity is over, register for beach volleyball championships. This would not be a bad thing, if managed with periods of discharge. Competitiveness is stressful and you risk arriving at the beginning of the next season with exhausts and physical problems. Beach volleyball develops very well some physical qualities such as anaerobic ability and recovery, but it is insufficient as a tendon training because of the playing surface that does not return the elastic work.

C. Balanced and planned maintenance activities. A balanced work surface must keep in mind precise objectives that rotate on development and not only on maintaining the condition of an athlete. (Ercolessi, 2002).

On the basis of what has been said, i.e. regularity and continuity, this study aims to investigate the motivation, thought and self-criticism of athletes in continuing their training activity even during the transition period (Gaetano, 2016).

\section{METHODS}

For this research the case study was chosen because it allows to place emphasis on the detailed contextual analysis of a limited number of events or conditions and their relationships. The sample was constructed using a non-probabilistic sampling procedure, subdividing the groups by characteristics such as gender and age.

To investigate this, a questionnaire was administered through a special online platform, in total anonymity so as not to run into false data. The study is submitted to volleyball athletes of different sexes and ages. The study involved 67 athletes divided into 3 groups: 19 boys aged between 18 and 29 years, 22 girls aged between 13 and 18 years and 26 other girls aged between 19 and 30 years.

Therefore, the approach is qualitative and quantitative, adopting a structured questionnaire as a survey tool. The contents are established a priori, standardization with reference to the uniformity of the stimuli offered and high structuring as the respondent cannot come out of the established trace. 
To avoid external influences in the respondents was decided to administer the questionnaire through the online platform google drive "forms".

In order to assess the quality of the instrument, a pre-test with similar characteristics was carried out prior to administration. The attention has allowed to evaluate the effectiveness of the tool by identifying some distortions arising from the articulation of the questionnaire. The pre-test suggested important methodological indications to refine the specification of the most relevant concepts of the research, for their operational definition and, therefore, for the final drafting of the questionnaire: for example, some indicators were revised, eliminating those semantically redundant or invalid compared to the indicated size.

The questions in the questionnaire are all closed-ended. For the articulation of the themes dealt with, filter questions were also included.

The main theme of the questionnaire is the transition period, we initially investigated the motivation to train in this period and how many times. In another section as a filter question, preference was asked to train individually, in groups or both.

The development of this choice investigates the preferred ways of planning and conducting training. The final section, instead, was dedicated to the survey of the values that children associate with sport, in particular volleyball (for example. How much do you love this sport? What level do you hope to reach?).

\section{RESULTS}

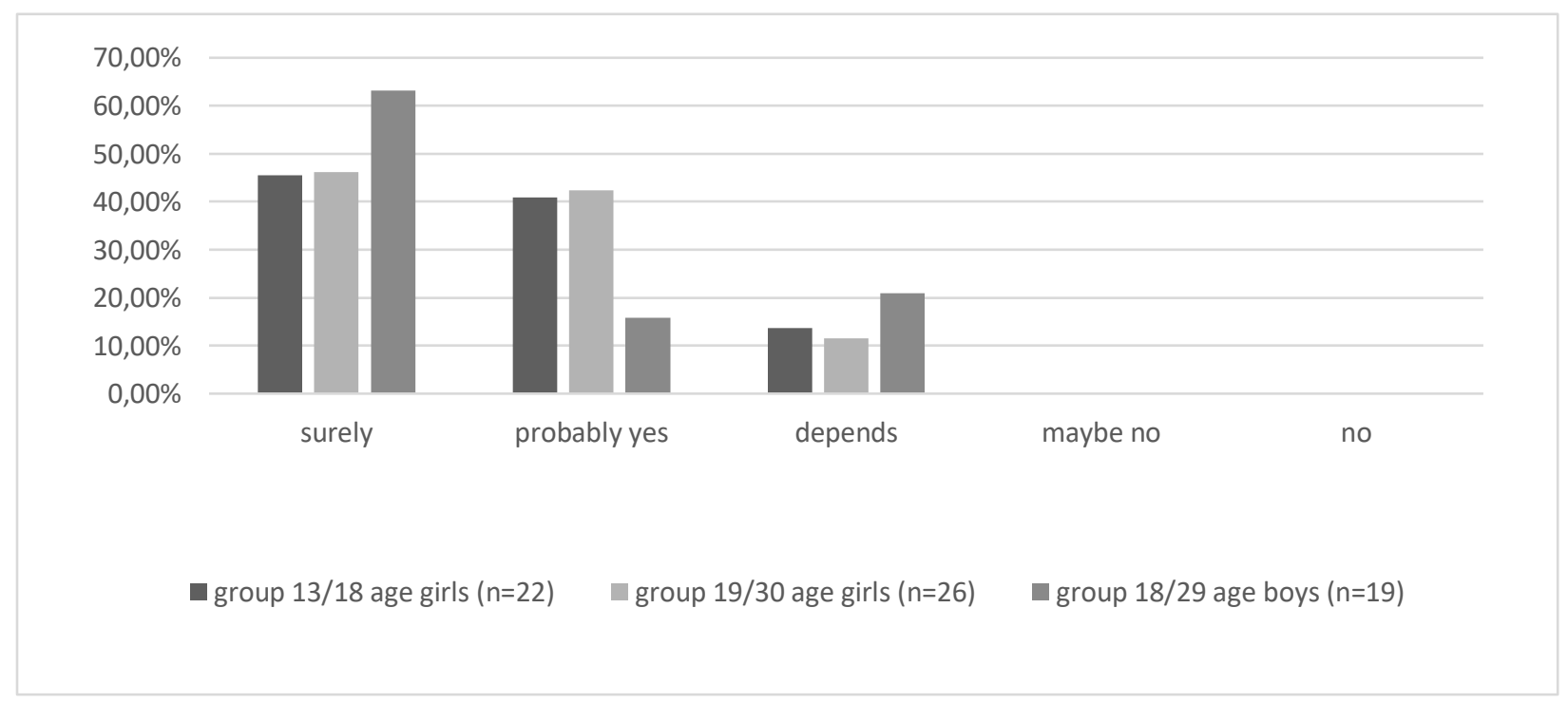

Figure 1. Answers A. 


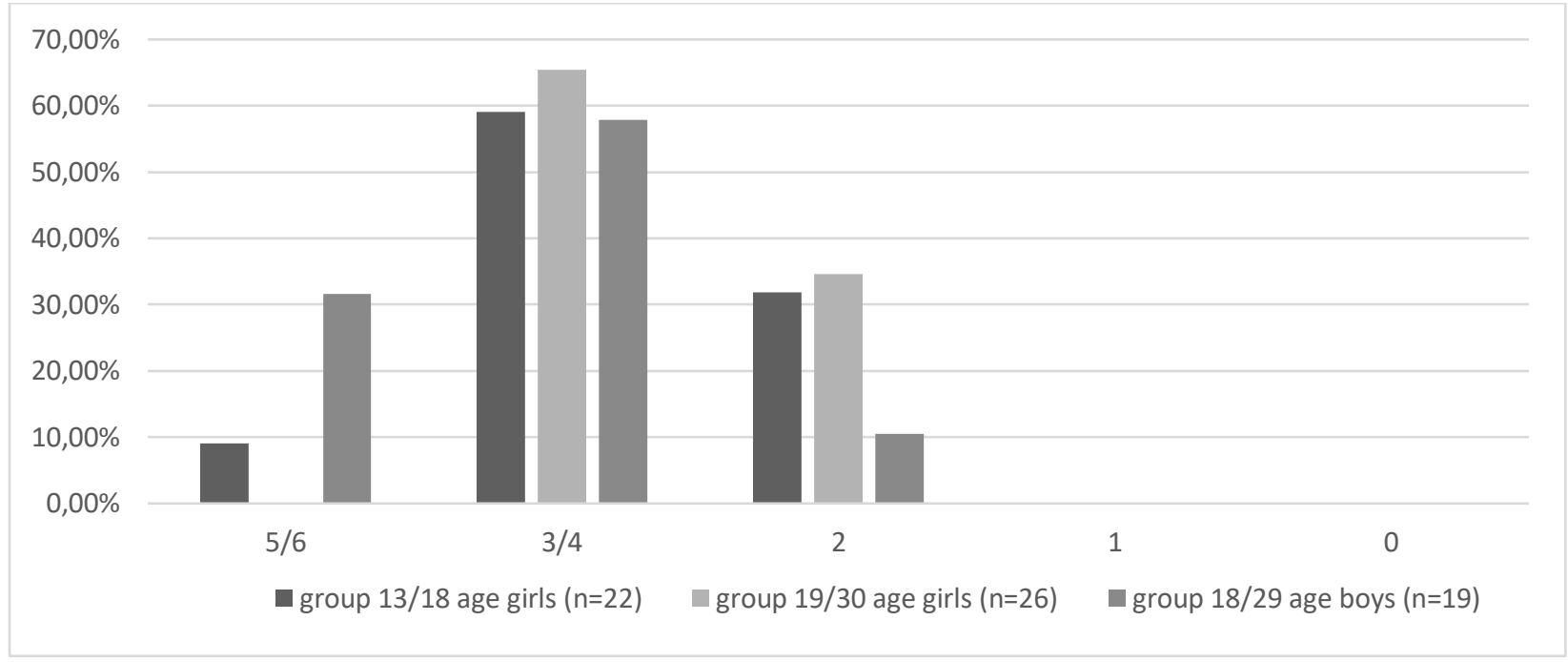

Figure 2. Answers B.

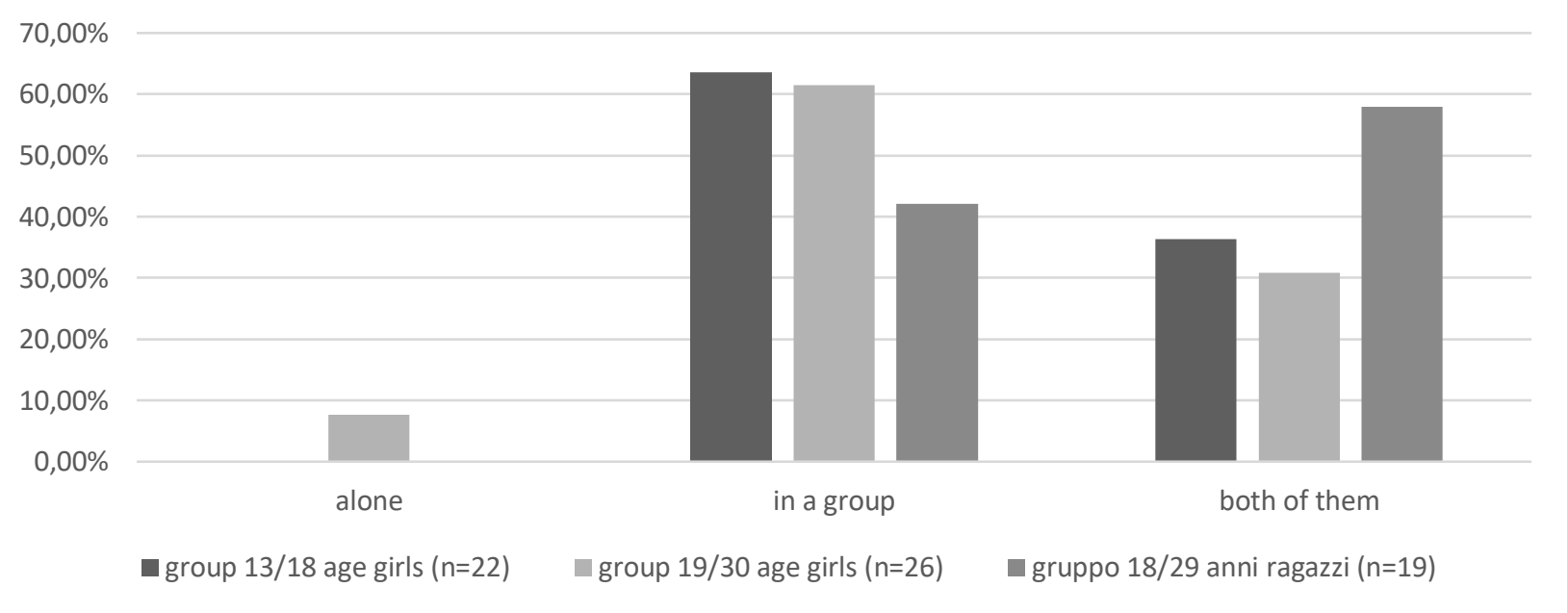

Figure 3. Answers $C$.

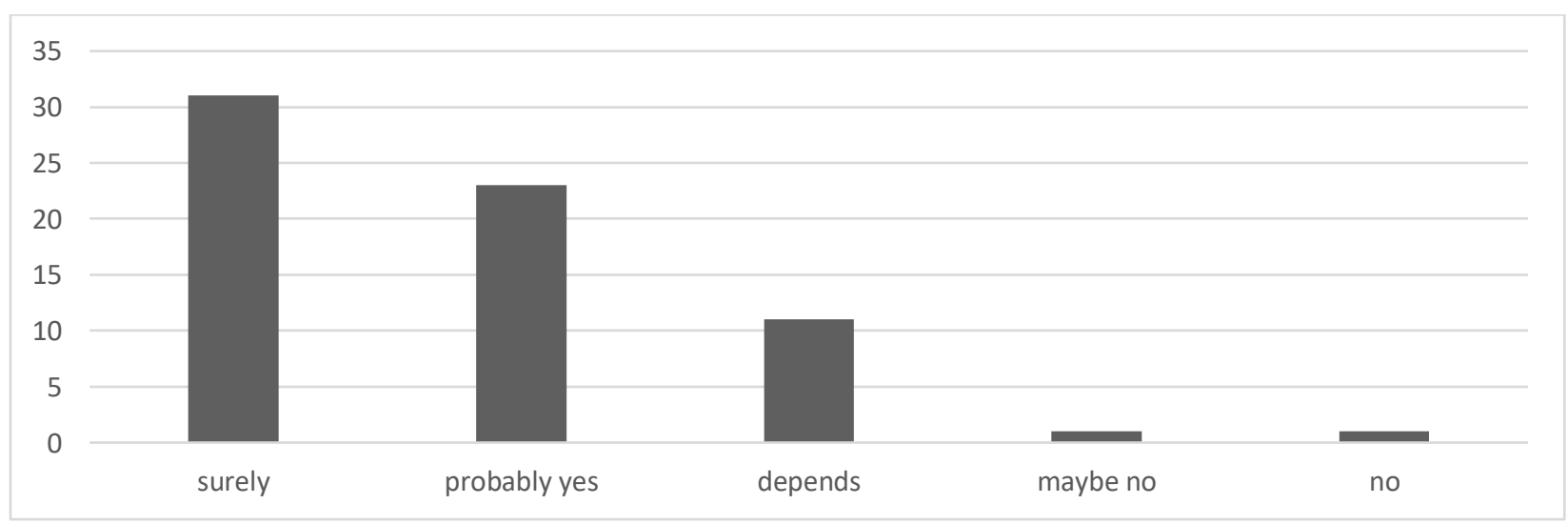

Figure 4. Answers D. 


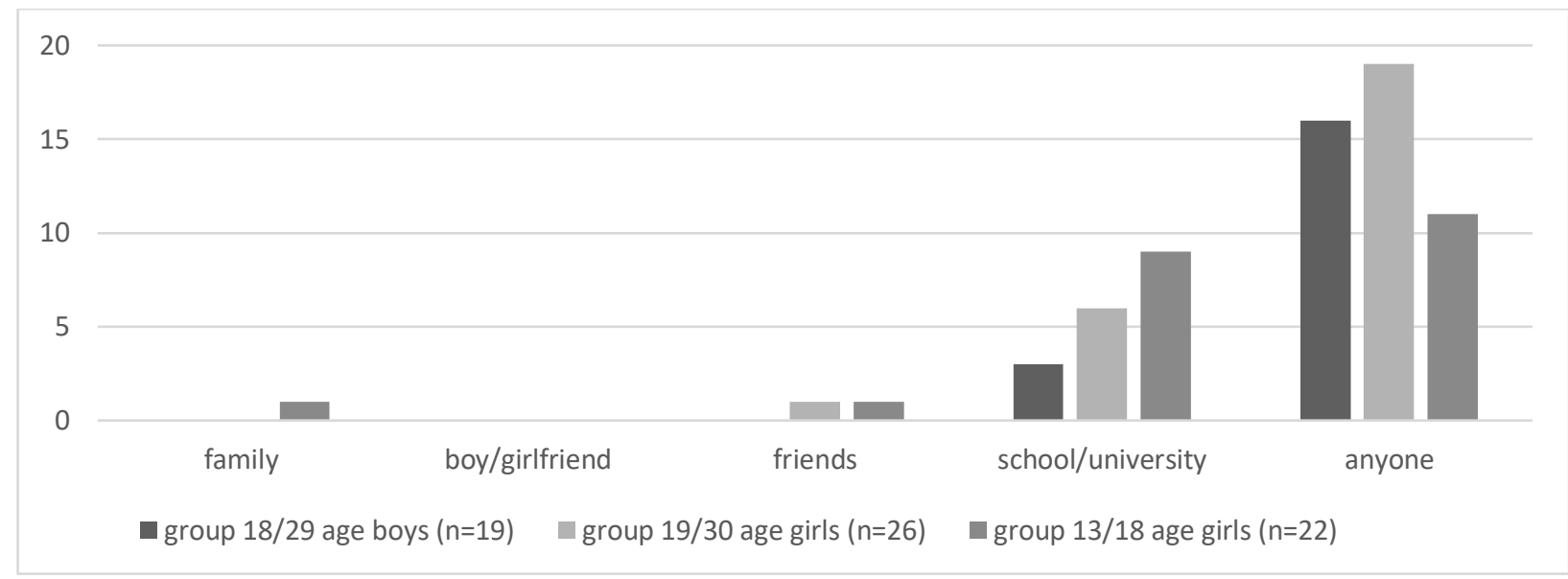

Figure 5. Answers D.

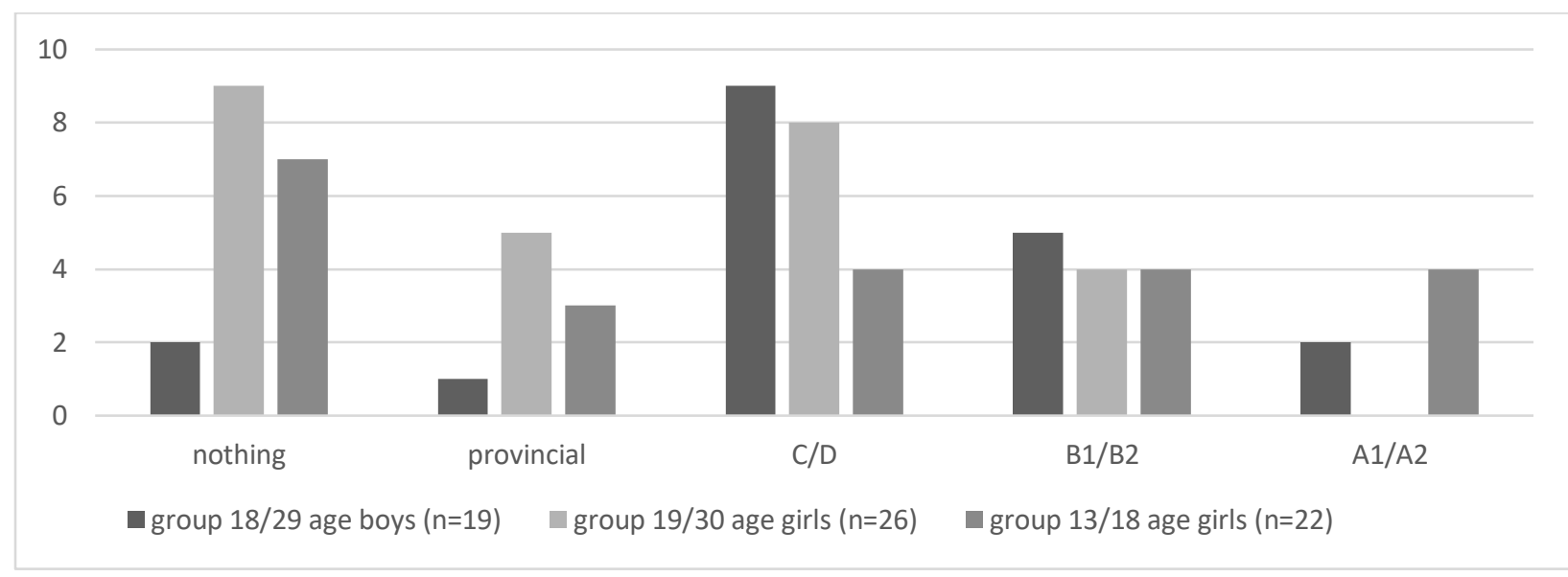

Figure 6. Answers $\mathrm{E}$.

\section{DISCUSSIONS}

This research stems from the desire to deepen knowledge about the transition period, and encourage companies to invest and continue their activities during this period, because as can be seen from previous research carried out on this period ( ) there is a significant reduction in performance that could be limited by implementing corrective measures to the inactivity of athletes, but to do this also had to be investigated the other side of the coin, namely the propensity and willingness of athletes to continue their activities.

\section{CONCLUSIONS}

The data shows the willingness and motivation to continue training activities even during the transition period. To the question: At the end of the sporting year, would you be in favour of continuing to train? About $80 \%$ of the answers are positive, only $20 \%$ are in doubt (Figure 1 ).

Even more evident if we consider the frequency with which athletes would participate. 
How many times would you prefer to train a week? From the answers we can see the propensity to train at almost the same pace as the competitive period (Figure 2).

Interesting is the tendency to leave the decision on the planning of activities to the figure of the coach (Figure 4): Would you prefer that it is the coach to plan a specific program? regardless of the choice of training alone, in groups or both. Would you rather train alone or in a group? About $60 \%$ would prefer to continue training in groups, emphasizing the aggregative factor of this sport, the rest would still like to train in groups but with the addition of specific training programs to be carried out even alone (Figure 3 ).

Another dimension investigated concerns the possible obstacles faced by athletes Who/what hinders your passion for volleyball? (Figure 5), and the results show that the main obstacle is the commitment due to the school / university.

With respect to the aspirations of the various athletes interviewed, what is the maximum level you hope to reach? (Figure 6) if you compare the answers you see that although the results are distributed over a medium to low level, you see that few athletes, especially boys aspire to high levels of competition.

The trip conducted in this research on the sample of athletes interviewed, has brought a positive result in order to achieve the goal of investing and continuing activities during this period.

\section{REFERENCES}

Altavilla, G., Mazzeo, F., D'Elia, F., Raiola, G. (2018). Physical commitment and specific work for each role in an elite soccer team, Journal of Physical Education and Sport, 18 (2): 570-574.

Altavilla, G., D'Isanto, T., Di Tore, A.P., Raiola, G. (2018). Free throw and outcomes: Pilot study on intensive training versus extensive one, Journal of Human Sport and Exercise, 13 (3): 494-503. https://doi.org/10.14198/ihse.2018.133.02

Altavilla, G., D'Isanto, T., \& Di Tore, P. (2018). Anthropometrics characteristics and jumping ability in basketball. Journal of Human Sport and Exercise, 13(2proc), S385-S392. https://doi.org/10.14198//hse.2018.13.Proc2.22

Altavilla, G., Di Tore, P.A., Riela, L., D'Isanto, T. (2017). Anthropometric, physiological and performance aspects that differentiate male athletes from females and practical consequences, Journal of Physical Education and Sport, 17: 2183-2187.

Cirillo, G., Nughes, E., Acanfora, A., Altavilla, G., D'Isanto, T. (2016). Physical and port education testing by quantitative and qualitative tools in assessment in senior school: A proposal. Sport Science, 9: 97-101.

D'Elia, F., D'Isanto, T., \& Altavilla, G. (2019). Training and performance in the transition period. Journal $\begin{array}{llll}\text { of Human Sport and Exercise, 14(2proc), S258-S262. } & \end{array}$ https://doi.org/10.14198/ihse.2019.14.Proc2.15

D'Elia, F., Mazzeo, F., Raiola, G. (2018). The core curriculum in the university training of the teacher of physical education in Italy, Journal of Human Sport and Exercise, 13(Proc2): S413-S420. https://doi.org/10.14198/ihse.2018.13.Proc2.25

D'Isanto, T., D'Elia, F., Raiola, G., Altavilla, G. (2019) Assessment of sport performance: Theoretical aspects and practical indications, Sport Mont, 17 (1), pp. 79-82.

D'Isanto, T., Di Tore, P. A., Altavilla, G. (2018). Correlation of the anthropometric characteristics and the ability to jump in volleyball. Journal of Human Sport and Exercise, 13(2proc), S393-S400. https://doi.org/10.14198/ihse.2018.13.Proc2.23 
Di Tore, A.P., Raiola, G., D'Isanto, T. (2018). Situation awareness in sports science: Beyond the cognitive paradigm, Sport Science, 11 (1): 44-48.

Di Tore, P.A., Raiola, G. (2012). Case study on physical education and sport in Naples, Italy, Mediterranean Journal of Social Sciences, 3 (11): 471-476.

Ercolessi D. (2002) II salto nelle vacanze, Supervolley n. 7-8, http://www.italvolley.net/PREPARAZIONE\%20FISICA/Salto\%20vacanze\%20Ercolessi.pdf

Ferrara, F., Izzo, R., Ceciliani, A., Di Tore, A.P. (2019) Pilot study on the testing of Power Glove applied to volleyball, Journal of Human Sport and Exercise, 14 (Proc2), pp. S233-S238. https://doi.org/10.14198/ihse.2019.14.proc2.11

Forte D., Altavilla G., (2018) Preliminary correlation between anthropometric and performance data in volleyball about the transition period, Journal of Physical Education and Sport), 18,1994-1998. https://doi.org/10.14198/ihse.2018.13.Proc2.25

Gaetano, R. (2012). Motor learning and didactics into physical education and sport documents in middle school-first cycle of education in Italy, Journal of Physical Education and Sport, 12 (2): 157-163.

Gaetano, R. (2012). Didactics of volleyball into the educate program for coaches/trainers/technicians of Italian Federation of Volleyball (FIPAV). Journal of Physical Education and Sport, 12 (1): 25-29.

Gaetano, A. (2016). Relationship between physical inactivity and effects on individual health status, Journal of Physical Education and Sport, 16: 1069-1074.

Parisi, F., Raiola, G. (2014) The serve in under 12-13 Italian volleyball team, Journal of Human Sport and Exercise, 9, pp. S588-S591. https://doi.org/10.14198/ihse.2014.9.proc1.51

Raiola, G., D'Elia, F., Altavilla, G. (2018). Physical activity and sports sciences between European research council and academic disciplines in Italy. Journal of Human Sport and Exercise, 13(2proc), S283-S295. https://doi.org/10.14198//hse.2018.13.Proc2.13

Raiola, G. (2017). Motor learning and teaching method, Journal of Physical Education and Sport, 17: 2239-2243.

Raiola, G., Di Tore, P.A. (2017). Motor learning in sports science: Different theoretical frameworks for different teaching methods, Sport Science, 10: 50-56.

Raiola, G., D'isanto, T. (2016). Assessment of periodization training in soccer. Journal of Human Sport and Exercise, 11: 267-278. https://doi.org/10.14198/ihse.2016.11.Proc1.19

Raiola, G. (2014). Teaching method in young female team of volleyball, Journal of Physical Education and Sport, 14 (1): 74-78.

Raiola, G. (2014). Motor control and learning skills according to cognitive and ecological dynamic approach in a vision on behaviorism, cognitive, Gestalt and phenomenology theories, Mediterranean Journal of Social Sciences, 5 (15): 504-506. https://doi.org/10.5901/mjss.2014.v5n15p504

Raiola, G. (2013). Body knowledge and motor skills, Knowledge Cultures, 1 (6): 64-72.

Raiola, G., Di Tore, P.A. (2012). Statistical study on bodily communication skills in volleyball to improve teaching methods, Journal of Human Sport and Exercise, 7 (2): 468-488. https://doi.org/10.4100/ihse.2012.72.12

Raiola, G., Di Tore, P.A. (2012). Bodily communication skills and its incidence on female volleyball championship to enhance didactics, Journal of Human Sport and Exercise, 7 (2): 365-375. https://doi.org/10.4100/jhse.2012.72.03

Raiola, G., Di Tore, A. (2012). Non-verbal communication and volleyball: A new way to approach the phenomenon, Mediterranean Journal of Social Sciences, 3 (2): 347-356. https://doi.org/10.5901/mjss.2012.v3n2.347

Raiola, G. (2012). Bodily communication in volleyball between human and experimental sciences, Mediterranean Journal of Social Sciences, 3 (1): 587-597. 
Tiziana, D., Antonetta, M., Gaetano, A. (2017). Health and physical activity, Sport Science, 10 (1): 100 105.

\section{(c) $($ ) $९$}

This work is licensed under a Attribution-NonCommercial-NoDerivatives 4.0 International (CC BY-NC-ND 4.0). 